\title{
Simulation of the spatio-temporal extent of groundwater flooding using statistical methods of hydrograph classification and lumped parameter models
}

\author{
Upton, K.A. and Jackson, C.R. \\ British Geological Survey, Kingsley Dunham Centre, Keyworth, Nottingham, NG12 5GG, UK \\ Corresponding author: C.R. Jackson (crja@bgs.ac.uk)
}

\begin{abstract}
This article presents the development of a relatively low cost and rapidly applicable methodology to simulate the spatio-temporal occurrence of groundwater flooding in chalk catchments. In winter 2000/2001 extreme rainfall resulted in anomalously high groundwater levels and groundwater flooding in many chalk catchments of northern Europe and the southern United Kingdom. Groundwater flooding was extensive and prolonged, occurring in areas where it had not been recently observed and, in places, lasting for 6 months. In many of these catchments, the prediction of groundwater flooding is hindered by the lack of an appropriate tool, such as a distributed groundwater model, or the inability of models to simulate extremes adequately. A set of groundwater hydrographs is simulated using a simple lumped parameter groundwater model. The number of models required is minimized through the classification and grouping of groundwater level time-series using principal component analysis and cluster analysis. One representative hydrograph is modelled then transposed to other observed hydrographs in the same group by the process of quantile mapping. Timevariant groundwater level surfaces, generated using the discrete set of modelled hydrographs and river elevation data, are overlain on a digital terrain model to predict the spatial extent of groundwater flooding. The methodology is applied to the Pang and Lambourn catchments in southern England for which monthly groundwater level time-series exist for 52 observation boreholes covering the period 1975-2004. The results are validated against observed groundwater flood extent data obtained from aerial surveys and field mapping. The method is shown to simulate the spatial and temporal occurrence of flooding during the 2000/2001 flood event accurately.
\end{abstract}

\section{Keywords}

groundwater flooding; chalk; hydrograph classification; lumped parameter model 


\section{INTRODUCTION}

Groundwater flooding was widespread across much of northern Europe (Pinault et al., 2005; Korkmaz et al., 2009) and the southern United Kingdom (Robinson et al., 2001; Finch et al., 2004; Adams et al., 2008) during and after the exceptionally wet winter of 2000/2001. This particular flood event resulted from a combination of high antecedent groundwater levels due to higher than average rainfall during the three subsequent winters from 1997 to 1999 and extreme meteorological conditions, whereby monitored rainfall between September and December 2000 was more than $180 \%$ of the long-term average value across much of southern England (Marsh and Dale, 2002). Flooding was prolonged, in some catchments lasting for up to 6 months, and resulted in financial losses in excess of $£ 1$ million in the United Kingdom alone (Green et al., 2006). It is possible that the risk of groundwater flooding will be exacerbated by anthropogenic climate change which, according to current climate models, is very likely to cause an increase in the frequency of heavy precipitation events over most areas of the globe during the 21st century (Bates et al., 2008). Chalk catchments are particularly affected by groundwater flooding due to their characteristic dual permeability and low storativity which allows significant and rapid increases in the level of the water table following prolonged and/or extreme rainfall. The development of a modelling tool for groundwater flood prediction is therefore required in order to: predict the likely impacts of climate change; quantify the risk in areas most vulnerable to groundwater flooding; and facilitate more accurate flood forecasting.

Flood frequency analysis has previously been used to estimate the T-year hydraulic head, which characterizes the groundwater surge for a given return period, $\mathrm{T}$, in a Mediterranean carbonate aquifer, allowing the magnitude of triggering rainfall events to be determined (Najib et al., 2008). However, groundwater flooding is generally strongly dependent on antecedent conditions and continuous simulation is therefore necessary to predict the temporal occurrence of flooding accurately. Furthermore, due to the complex processes involved in the generation of groundwater floods in chalk catchments, an accurate flood prediction tool would also require determination of the spatial extent of flooding. A modelling approach, whereby system processes are represented by transfer functions that define relationships between the input and output data, has previously been undertaken to simulate groundwater flooding in a karstic aquifer in southern France (Marechal et al., 2008). This approach was unable to produce an accurate simulation of the water table surface to simulate the amount of overflow but was able to simulate the occurrence of overflow during 
high rainfall events allowing determination of a rainfall threshold for flooding. Regional numerical groundwater models are able to predict the spatial and temporal distribution of storage in an aquifer and have potential application in flood risk assessment. Korkmaz et al. (2009) applied a coupled surface — unsaturated — groundwater model (MODCOU) to simulate the 2000/2001 floods in the Somme River Basin obtaining a satisfactory representation of groundwater behaviour, its effect on surface flow and the magnitude and spatial extent of groundwater emergence at the surface during the flood of 2000/2001. However, distributed groundwater models are expensive to develop and often difficult to calibrate to groundwater levels in chalk aquifers because of their spatial heterogeneity. At present, no cost-effective and rapidly applicable tool exists for the accurate simulation of the spatial and temporal extent of groundwater flooding in chalk catchments.

This article presents a relatively simple and widely applicable tool for the simulation of the spatio-temporal occurrence of groundwater flooding in chalk aquifers. The methodology involves the generation of time-variant groundwater level surfaces from a series of point models and river elevation data which can be overlain on a digital terrain model, highlighting areas of groundwater emergence. The number of models required is minimized through the classification and grouping of groundwater level time-series using principal component analysis (PCA) and cluster analysis (CA). PCA is a form of factor analysis that is commonly used to reveal variations and patterns in datasets allowing variables with the highest correlation to be grouped together. In the field of hydrological science, PCA has previously been used to: (1) define patterns in groundwater hydrographs in order to understand the areal distribution of different recharge characteristics and to determine if fewer wells can be measured for long-term groundwater monitoring without significant loss of information (Winter et al., 2000); (2) classify diurnal stream hydrographs to characterize seasonal and downstream changes in diurnal outflow in glacier basins (Hannah et al., 2000); and (3) identify the spatial distribution of homogenous recharge zones from groundwater hydrographs displaying similar fluctuation patterns (Moon et al., 2004). In this study, PCA is used to combine groundwater hydrographs into a small number of groups displaying similar fluctuation patterns, for which one representative hydrograph can be modelled. Each of the representative master hydrographs is simulated using a simple lumped parameter model. Modelled hydrographs are then transposed to other locations using quantile mapping, allowing spatial interpolation of groundwater levels at any given point in time. The methodology is presented with reference to the Pang and Lambourn catchments in southern 
England, which experienced widespread flooding during the winters of 2000/2001 (Finch et al., 2004) and 2002/2003. Monthly groundwater level time-series are available for 52 observation boreholes across the catchments for which four representative models are developed. The models are calibrated over the period 1989-2002, incorporating the extreme flood event of 2000/2001 and are validated over the period 1975-1989 and against the winter 2002/2003 groundwater flood event.

\section{STUDY AREA}

The Pang and Lambourn catchments are situated in the Berkshire Downs on the northwestern margin of the Lon don Basin, UK (Figure 1). These catchments are typical of many chalk catchments in the United Kingdom and northern Europe and have been the subject of numerous hydrogeological studies. As a result, the extent of flooding during the winter of 2000/2001 is well documented providing observational data against which this methodology can be evaluated. The catchments are predominantly rural, covering an area of approximately $400 \mathrm{~km}^{2}$. Average annual rainfall is $730 \mathrm{~mm}(1975-2005)$ on the interfluves of the Lambourn catchment, decreasing to an average of $678 \mathrm{~mm}$ in the lower Pang catchment. The Pang and Lambourn rivers are tributaries of the Thames and Kennet, respectively. Groundwatersurface water interactions have been studied extensively in both catchments (Grapes et al., 2005; Griffiths et al., 2006). River-aquifer interactions are highly complex and dependent on groundwater level, the thickness, extent and composition of superficial deposits, the presence of springs and dry valleys and the development of water management structures such as weirs. Flow accretion is continuous along the River Lambourn with base flow indices ranging from 0.84 in the lower reaches to 0.97 in the upper reaches (Griffiths et al., 2006). Accretion is more variable along the length of the River Pang. There is a marked difference in the perennial and ephemeral heads of the two rivers, highlighting the importance of seasonal groundwater discharge to the rivers (Brad ford, 2002). Springs also form important discharge points for the Chalk and are concentrated along the base of the Chalk escarpment in the north, along the valleys of the main rivers and their tributaries, and along the Palaeogene-Chalk contact in the south-east of the area.

The geology of the area is dominated by the Cretaceous Chalk which dips gently towards the south-east forming a scarp slope along the northern margin of the catchments. The Chalk is underlain by the Albian age Upper Green sand sandstone and is overlain by Palaeogene clay, sand and gravel deposits of the Thames and Lambeth Groups, which are locally confining in 
the south (Figure 1). Flow within the saturated zone of the Chalk occurs predominantly in the upper $50 \mathrm{~m}$ of the profile through primary and secondary fractures (Allen et al., 1997). Lateral and vertical variations in transmissivity and storativity exist due to variation in the fracture density, which is con trolled by the depth and location within the catchment (Allen et al., 1997; Williams et al., 2006). Hydraulic conductivity is generally highest in the zone of water table fluctuation and in the major valleys and dry valleys where fractures have been developed by dissolution, and is lowest at depth and on the interfluves (Allen et al., 1997). The Chalk stratigraphy also exerts a control on aquifer properties. For example, the basal Zig Zag and West Mel bury Chalk members are relatively clayey and have a lower hydraulic conductivity. Data from 117 pumping tests carried out at 74 boreholes in the Kennet Valley give transmissivity values ranging from 0.5 to $8000 \mathrm{~m}^{2} \mathrm{~d}^{-1}$. The data have a geometric mean equal to $620 \mathrm{~m}^{2} \mathrm{~d}^{-1}$ and a median value of $830 \mathrm{~m}^{2} \mathrm{~d}^{-1} ; 25 \%$ of the data are less than $380 \mathrm{~m}^{2} \mathrm{~d}^{-1}$ and $75 \%$ are less than $1500 \mathrm{~m}^{2} \mathrm{~d}^{-1}$ (Allen et al., 1997). Regional groundwater flow is con trolled by the base levels set by the River Thames and River Kennet and is predominantly to the south-east. The Pang and Lambourn rivers and numerous springs act as local, seasonally variable controls on groundwater flow.

The primary mechanism for flow in the unsaturated zone of the Chalk has been the subject of many studies since the 1980s (for example see Wellings, 1984; Price et al., 2000; Mahmoodul-Hassan and Gregory, 2002; Mathias et al., 2005; Ireson et al., 2006; Ireson et al., 2009). It is generally accepted that fluxes within the unsaturated zone are transmitted through the matrix until they exceed the saturated hydraulic conductivity of the matrix, at which point fracture flow becomes dominant (Ireson et al., 2006). Previous studies have shown, however, that the generation of fracture flow is rare and for the majority of the time fluxes are transmitted by the matrix (Mathias et al., 2005). Depending on the water content of the unsaturated zone, transfer of recharge through the matrix may occur by flow through the pore space or by the piston displacement mechanism (Lee et al., 2006). Transfer by piston displacement allows for a rapid response of the water table without the generation of fracture flow and the response time will decrease further if fracture flow is initiated. This, along with the low storage capacity of the unsaturated zone, can result in significant and rapid increases in the level of the water table following prolonged and extreme rainfall. Groundwater flooding in response to extreme rainfall can occur by two mechanisms (Finch et al., 2004): (1) emergence onto a floodplain from saturated alluvial deposits and (2) emergence at the surface in the upper reaches of streams or rivers from permeable strata. Unconfined chalk 
aquifers are particularly susceptible to groundwater flooding by the second mechanism whereby the water table reaches the land surface in topographically higher regions of a catchment resulting in ephemeral stream flow or the activation of springs.

During the floods of 2000/2001, peak monthly rainfall occurred in October 2000 in the Pang and Lambourn catchments. Groundwater levels initially peaked between December 2000 and January 2001 but remained high through to March 2001, and river flows peaked between December 2000 and February 2001 but remained higher than average throughout much of 2001 due to increased baseflow. Groundwater flooding occurred due to rising water tables within the upper, normally dry valleys. The areas worst affected in the Lambourn catchment include Upper Lambourn village and the dry valley at Great Shefford, and in the Pang catchment include West and East Ilsley and Hampstead Norreys (Figure 1). There was extensive flooding of land, roads and properties, some of which were continuously pumped out until May 2001 (Robinson et al., 2001).

\section{HYDROGRAPH CLASSIFICATION}

\section{Statistical Methods}

Groundwater level time-series represent an integration of recharge, storage and flow processes within a catchment. Differences between chalk hydrographs can be quantified in an objective, efficient and repeatable way using statistical methods of hydrograph classification. Hydrograph classification and grouping has been undertaken according to the method outlined by Hannah et al. (2000) using a combination of PCA and CA. A brief explanation of PCA and CA is given here; a detailed explanation can be found in Davis (1986). PCA is a form of factor analysis that decomposes a correlation or covariance matrix to express large multivariate datasets in a reduced number of variable dimensions, termed principal components. It is commonly used in exploratory data analysis to reveal variations and patterns in datasets allowing variables with the highest correlation to be grouped together. In this study three components are required to retain $>95 \%$ of the variance of the original dataset. Hierarchical CA (using Pearson's correlation coefficient and the complete linkage method) is then carried out on the component loadings, which are effectively a measure of the similarity between each original variable and each principal component. A cluster validity index (based on the root mean square standard deviation) is calculated for each cluster at each step of the process, giving a measure of the homogeneity of the clusters that have been formed. This allows groundwater hydrographs to be combined into an optimum 
number of groups displaying similar fluctuation patterns for which one representative hydrograph can be modelled.

Groundwater hydrographs from 52 observation boreholes within the Pang and Lambourn catchments have been analysed. The frequency of observations is not consistent in time or space and therefore groundwater levels are initially interpolated onto the first day of every month. Interpolation is only allowed when the time period between successive observations is less than 60 days. Where this is not the case, the hydrograph is considered to be incomplete. Approximately two-thirds of the hydrographs have varying lengths of missing data, commonly between 1983 and 1989 and from 1997 onwards. In order to maximize the number of data points available, three time periods are identified during which the greatest number of boreholes have complete observational records: 1975-1983 and 1989-1997 (each with 40 complete records), and 1991-2004 (27 complete records). Groundwater levels are normalized and a PCA is performed for each of the three time periods. The covariance matrix of the normalized dataset is initially calculated, and the eigenvectors and eigenvalues of this matrix are found. These are then used to calculate the component scores and loadings. Separate cluster analyses are then carried out on the component loadings from each of the three principal component analyses and the results are combined. PCA and CA are carried out using the $\mathrm{R}$ software environment. The 52 observation boreholes are distributed at an average density of approximately 1 per $8 \mathrm{~km}^{2}$; however, there is a greater concentration across the western part of the Pang catchment and in the lower Lambourn catchment.

\section{Classification Results}

Initial CA of the component loadings identifies two statistical anomalies (the time-series for the Longacre and Winterbourne boreholes) which consistently form stray strands on the dendrogram plot. These are removed from the analysis and considered as single entities. The CA results based on the component loadings of the 1975-1983 PCA time period are presented in a dendrogram and validity index plot (Figure 2). The results from all three analyses indicate that four is the optimum number of groups as this gives the smallest number of clusters without significantly increasing the intra-cluster root mean square standard deviation. Figure 3 shows the standardized hydrographs in groups 1 and 4 identified by PCA and CA. Hydrographs within group 1 display relatively constant minima with high amplitude fluctuations. Group 4 hydrographs display greater inter-annual variability and small amplitude fluctuations. Groups 2 and 3 represent a continuum from groups 1-4. 
Variations in the groundwater fluctuation patterns will be determined by a range of factors that are difficult to characterize, for example local recharge patterns, the thickness of the unsaturated zone, the structure of the chalk and local hydrogeological controls such as rivers. However, a broad spatial distribution of the groups can be seen in Figure 4. There is a concentration of group 1 boreholes in the Upper Lambourn and group 4 boreholes in the Upper Pang. Groups 2 and 3 are distributed across the interfluves with a greater concentration of group 2 in the Lambourn catchment and group 3 in the Pang catchment. The anomalous boreholes are situated in major dry valleys. One borehole for which a complete time-series is available is randomly selected from each hydrograph group (Baydon Hole, group 1; Inholmes, group 2; Gibbet Cottages, group 3; Woodend, group 4). Groundwater hydrographs from each borehole listed above, along with the two anomalous boreholes, are simulated individually using a simple lumped parameter model.

\section{GROUNDWATER HYDROGRAPH SIMULATION \& TRANSPOSITION}

\section{Model Structure}

The model used in this study is a coupled recharge-aquifer model based on the models presented by Calver (1997) and Keating (1982). Recharge from the base of the soil zone has been derived from a previous modelling study (Jackson et al., 2005), which applies the distributed recharge model, ZOODRM (Mansour \& Hughes, 2004), to the regional aquifer system of the Marlborough and Berkshire Downs and South-West Chilterns. This model takes into account daily rainfall derived from Thiessen polygons of 57 rain gauges and gridded long-term average rainfall, monthly potential evaporation, and monthly run-off to determine the amount of excess rainfall. It then applies the Penman-Grindley Soil Moisture Deficit method (Penman, 1948; Grindley, 1967), using gridded land-use distribution and associated crop root constants and wilting points, to calculate the evapo-transpiration and recharge. Recharge is also influenced by surface water run-off (surface water as percentage of rainfall) and run-on (recharge to the adjacent node as a percentage of run-off). The model outputs a distributed, monthly-averaged recharge, which has been extracted at the borehole locations, providing a monthly time-series.

A commonly applied transfer function as used by Calver (1997) is the basis for the transfer of recharge from the base of the soil zone through the unsaturated zone to the water table. Recharge from the base of the soil in each month is applied to the water table over a number of subsequent months. The number of months, $n$, over which recharge is distributed is a 
model parameter. The distribution of recharge over the $n$ months is specified using a twoparameter Weibull probability density function, which can represent exponentially increasing, exponentially decreasing and positively and negatively skewed distributions. These distributions are smooth and have been used because they are considered to be more physically justifiable than randomly selected monthly weights.

The aquifer is represented by a block that is assumed to be unconfined and is drained by a stream with a perennial $\left(\mathrm{Q}_{\mathrm{p}}\right)$ and ephemeral $\left(\mathrm{Q}_{\mathrm{w}}\right)$ flow component (Figure 5). A third discharge component $\left(\mathrm{Q}_{\mathrm{a}}\right)$ is added at the base of the system to represent groundwater discharge below the level of the perennial stream. For this model, groundwater head may fall beneath the level of the perennial stream $\left(h_{p}\right)$ but will always be above the base level of groundwater discharge $\left(h_{a}\right)$. Hydraulic conductivity and storativity are distributed with depth so the section of the aquifer discharging to the ephemeral stream is characterised by high hydraulic conductivity $\left(\mathrm{K}_{\mathrm{w}}\right)$ and storativity $\left(\mathrm{S}_{\mathrm{w}}\right)$, representing the more permeable zone within the range of water table fluctuation. These parameters decrease with depth so the perennial stream is fed by a zone of lower hydraulic conductivity and storativity $\left(K_{p}\right.$ and $\left.S_{p}\right)$. Hydraulic conductivity and storativity decrease linearly from the base of the ephemeral stream level $\left(h_{w}\right)$ to a defined level above that of the perennial stream level $\left(h_{b}\right)$.

The lumped parameter model is based on the mass balance equation:

$$
\mathrm{R} \Delta \mathrm{x} \Delta \mathrm{y}-\mathrm{Q}_{\mathrm{w}}-\mathrm{Q}_{\mathrm{p}}-\mathrm{Q}_{\mathrm{a}}=\mathrm{S} \Delta \mathrm{x} \Delta \mathrm{y} \cdot \delta \mathrm{h} / \delta \mathrm{t}
$$

where $\mathrm{R}$ is recharge $\left[\mathrm{LT}^{-1}\right], \Delta \mathrm{x}$ and $\Delta \mathrm{y}$ are the length and width of the aquifer [L], $\mathrm{Q}_{\mathrm{w}}$ and $\mathrm{Q}_{\mathrm{p}}$ are the groundwater discharge to the ephemeral $(w)$ and perennial $(\mathrm{p})$ stream components $\left[\mathrm{L}^{3} \mathrm{~T}^{-1}\right], \mathrm{Q}_{\mathrm{a}}$ is groundwater outflow $\left[\mathrm{L}^{3} \mathrm{~T}^{-1}\right], \mathrm{S}$ is the storage coefficient [-], $\delta \mathrm{h}$ is the change in groundwater head $[\mathrm{L}]$ over time, $\delta \mathrm{t}[\mathrm{T}]$ and $\mathrm{h}$ is the groundwater head $[\mathrm{L}]$. The discharge terms, $\mathrm{Q}$, are calculated using equations of the form:

$$
\mathrm{Q}=\frac{\mathrm{T} \Delta \mathrm{y}}{0.5 \Delta \mathrm{x}} \Delta \mathrm{h}
$$


where $\Delta \mathrm{h}[\mathrm{L}]$ is the difference between the groundwater head and the elevation of the outlet below or the difference in elevation between two outlets, depending on the current groundwater head, and $\mathrm{T}$ is the appropriately calculated transmissivity $\left[\mathrm{L}^{2} \mathrm{~T}^{-1}\right]$.

\section{Model Application}

The lumped parameter model utilizes a Monte Carlo simulation to identify model parameter sets that give the best fit to the observed data. Because of the equifinality thesis (Beven, 2003), no attempt is made to search for an optimum parameter set using, for example automatic global optimization techniques (see for example Duan et al., 1992; Kuczera and Parent, 1998; Vrugt et al., 2003a,b, 2005). The recharge-groundwater model has an 11dimensional parameter space (parameters are listed in Table I). It has been suggested that in order to comprehensively sample the entire parameter space, each parameter should equate to an order of magnitude increase in the number of model runs (Beven, 2001). A Monte Carlo run of 1000 simulations of the 14-year calibration period using a monthly time step requires a computational time of approximately $3 \mathrm{~min}$; undertaking $10^{11}$ simulations is therefore not feasible. Instead, a two-stage Monte Carlo approach is adopted. The initial stage gives an indication of the parameter values that are able to produce a good fit to the observed data, allowing preferential sampling of parameters in the final stage. Six groundwater hydrographs, including one representative hydrograph from each of the four groups and the two statistically anomalous hydrographs, are simulated. For the first stage (referred to as the initial Monte Carlo run), a set of 100,000 model simulations is undertaken for each hydrograph. Broad parameter ranges are defined a priori for each input parameter (Table I). The ranges for the eight aquifer parameters are defined based on hydrogeological knowledge of the Chalk (Allen et al., 1997), and values are sampled randomly from a uniform distribution of the predefined ranges. The three recharge model parameters include: (1) the maximum number of months, n, over which recharge can be distributed; (2) the shape parameter, $\mathrm{k}$, of the Weibull distribution; (3) the scale parameter, $\lambda$, of the Weibull distribution. The Weibull distribution parameters, $\mathrm{k}$ and $\lambda$, are randomly selected to generate different forms of the distribution, which are considered to be more physically justifiable than the generally irregular distributions derived by randomly selecting the monthly recharge weightings. The maximum number of months, $\mathrm{n}$, is informed by calculating the crosscorrelation function between each groundwater level and recharge time-series. The crosscorrelation is a measure of the similarity of the two time-series as a function of a time lag applied to one of them. The number of months over which recharge is distributed in the 
Monte Carlo run varies between 1 and $\mathrm{n}$ and is again randomly selected from a uniform distribution.

The model outputs from the initial Monte Carlo run are evaluated against the observed groundwater time-series using two objective functions: the root mean square error (RMSE) calculated on the extremes of the hydrograph (i.e. above or below the mean $\pm 1 \mathrm{SD}$ ) and the Nash-Sutcliffe criterion. This gives an indication of the model fit to both the full range and extremes of the observed hydrograph. Scatter diagrams of parameter values versus the objective functions of each model simulation indicate the parameters that are identifiable, i.e. tend towards a global optimum (Beven, 2001). For those parameters that are shown to be identifiable, the feasible parameter space is reduced such that the new parameter range brackets the best model from the initial Monte Carlo run. Where multiple optima exist within the parameter space, the a priori range is maintained. A final Monte Carlo run of 100,000 simulations is made using the reduced parameter space to produce a final set of calibrated models. This two-stage approach allows preferential sampling of the parameter space that is initially shown to produce a good fit to the observed data, removing the need to undertake $10^{11}$ model simulations for each hydrograph.

In order to ensure accurate simulation of the hydrograph extremes and to avoid complexities of transposing models outside the calibration range (considered further in the Discussion), models are calibrated over the period 1989-2002, incorporating the most extreme flood event of 2000/2001. Models are validated over the period 1975-1989 and against the winter $2002 / 2003$ groundwater flood. The single best model from the final simulation is run over the validation period, and then transposed to the other hydrographs within the same group by the process of quantile mapping.

It is beyond the scope of this article to undertake model prediction (i.e. simulations outside the observed time period) and therefore no formal assessment of model predictive uncertainty is made. However, in order to make a preliminary assessment of model uncertainty, and to address the issue of multiple parameter sets producing a good fit to the observed data, the best 50,000 calibrated models, based on the RMSE of the hydrograph extremes, are run over the validation period for one of the modelled hydrographs (e.g. Baydon Hole in group 1) and evaluated against the observed data. In order to assess model uncertainty when simulated hydrographs are transposed to other observed hydrographs, the 
set of validated models is then transposed to the other boreholes in the group, by the method of quantile mapping, and evaluated against the observed data using the objective functions as above.

\section{Model Transposition}

The quantile mapping technique is often used to correct a model output based on the empirical cumulative distribution functions (ECDF) of the observed and simulated datasets (Hashino et al., 2007). Each value within the simulated dataset is associated with a particular percentile in the simulated distribution. This percentile is mapped onto the ECDF of the observed dataset and the associated observed value becomes the bias corrected value in the simulated dataset.

Here quantile mapping is used to translate the four representative simulated hydrographs to multiple locations around the catchments. Comparison of the ECDF of two time-series requires that the data be for equivalent time periods therefore the missing sections of hydrographs are initially reconstructed from the representative hydrograph in each group. This is achieved by rescaling using the mean and standard deviation and is based on the assumption that the hydrographs in each group have identical standardised forms over the entire observational record (1975-2004). The root mean square error (RMSE) is calculated for each reconstructed hydrograph within the time period for which observed data are available, providing an estimation of the error of the reconstructed missing section. The minimum error (RMSE) for the reconstructed hydrographs in groups one to four is $0.42 \mathrm{~m}$, $0.17 \mathrm{~m}, 0.62 \mathrm{~m}$ and $0.51 \mathrm{~m}$, respectively; the maximum RMSE for each group is $2.01 \mathrm{~m}$, $2.39 \mathrm{~m}, 2.34 \mathrm{~m}$ and $1.32 \mathrm{~m}$.

The percentile of each value in the simulated groundwater time-series, over the entire calibration (1989-2002) and validation (1975-1989, 2002-2004) period, is determined from the ECDF of the simulated time-series over the calibration period only. This percentile is mapped onto the ECDF of an observed groundwater time-series (of the calibration period only) from another location and the associated value becomes the groundwater level in the constructed hydrograph for that location. The use of the quantile mapping technique transposes simulated hydrographs such that the probability distribution of the bias corrected values closely resembles that of the observed data. There should not, however, be a significant change in the signal of the simulated dataset, i.e. a simulated peak will always 
map onto a high observed value, and therefore the use of the hydrograph groupings for transposition should improve the fit of the bias corrected values to the observed data.

\section{RESULTS OF HYDROGRAPH SIMULATION}

\section{Model Results}

The parameter ranges defined for the initial and final Monte Carlo runs are shown in Table I. The results from the initial Monte Carlo run for each modelled hydrograph show that, in general, permeability and storativity controlling groundwater head at greater depths in the profile (Kp and $\mathrm{Sp}$ ) tend towards a global optimum and permeability and storativity of the upper profile (Kw and $\mathrm{Sw}$ ) display multiple optima over the entire range of permissible values. This is highlighted in Figure 6, which shows scatter plots of each aquifer parameter versus the RMSE calculated on the hydrograph extremes for the initial Monte Carlo run of Baydon Hole (representative hydrograph of group 1). In general, the results from the initial Monte Carlo run for each simulated hydrograph indicate that the best model results are obtained from a skewed normal distribution of recharge. However, different weightings of recharge over a varying number of months are able to produce equally good model results and therefore the recharge parameters are sampled from the a priori ranges in the final Monte Carlo run. The recharge distributions for the 200 best models from the final Monte Carlo run of Baydon Hole are shown in Figure 7. In these models monthly recharge is distributed over 3-5 months, with the highest proportion of recharge applied to months 2 and 3. The nonidentifiability of certain parameters and the ability of multiple values to produce an equally good fit to the observed data highlight the complex interaction between model parameters. The sensitivity of the model to the higher permeability, $\mathrm{Kw}$, and storativity, $\mathrm{Sw}$, are related to the discharge levels (ha, hp and hw ). The feasible range of hw lies close to the maximum groundwater level and therefore accounts for a smaller proportion of the total hydrograph range. Few model parameter sets therefore result in the mass balance being controlled by discharge, Qw . For each simulated hydrograph, the goodness of fit is improved in the final Monte Carlo run by reducing the parameter space for those parameters that are shown to be identifiable. This is highlighted in Figure 6, which shows the results from both the initial and final runs for Baydon Hole.

The simulated hydrographs of Baydon Hole (group 1) and Woodend (group 4), which represent the most diverse hydrograph groups, are shown in Figure 8 over the entire calibration and validation period. The RMSE (calculated on the hydrograph extremes) and 
Nash-Sutcliffe criterion for the calibration and validation time period of the six modelled hydrographs are shown in Table II. Within the calibration period, the Nash-Sutcliffe criterion is above 0.8 for the simulated hydrographs of groups $1-4$ indicating a good fit to the observed data. The hydrograph extremes are also simulated well within the calibration period, with an average RMSE (extremes) of $3 \mathrm{~m}$. The Nash-Sutcliffe criterion is lower $(0.61$ and 0.71 ) for the anomalous hydrographs; however, they show a good fit to the hydrograph extremes. There is a slight decrease in model performance over the validation period; however, the Nash-Sutcliffe criterions remain above 0.8 (with the exception of Woodend and the anomalous hydrographs) and the RMSE of the extremes remains below $3 \mathrm{~m}$ (with the exception of Gibbet Cottages).

The flood peaks of the 2000/2001 and 2002/2003 flood events are simulated well by all modelled hydrographs. The modelled hydrograph of Baydon Hole (group 1) accurately simulates the double peaks of the 2000/2001 flood event (January and March), both of which are underestimated by less than $1 \mathrm{~m}$. The January 2001 peak is underestimated by $4 \mathrm{~m}$ on the simulated hydrograph of Inholmes (group 2); however, the March peak is simulated to within $2 \mathrm{~m}$. The main flood peak on the observed hydrograph of Gibbet Cottages (group 3) occurs in March and is simulated to within $1.5 \mathrm{~m}$. The modelled hydrograph of Woodend (group 4) underestimates the magnitude of the observed flood peak by only $0.8 \mathrm{~m}$, however, simulates the peak in March not January. The observed peaks on the anomalous hydrographs are both simulated to within $0.5 \mathrm{~m}$. The 2003 flood peak, which is within the validation period, occurs in February. The modelled hydrographs of Gibbet Cottages and Woodend overestimate the flood peak by less than 1 and $2.5 \mathrm{~m}$, respectively, but simulate the peak in March. The modelled hydrograph of Baydon Hole also overestimates the flood peak by less than $1 \mathrm{~m}$ but simulates the peak in January. The timing of this peak is simulated accurately by the Inholmes and Longacre models to within $0.25 \mathrm{~m}$ of the observed value.

The spread of the simulated time-series of the 50,000 best models for Baydon Hole, over the calibration and validation time period, is shown in Figure 8A. The difference in validated results for the models is relatively small, suggesting that the uncertainty of the validated model results attributable to input parameter uncertainty is low. It does not, however, follow that predictive uncertainty would also be low, particularly if prediction involved simulation outside the calibration and validation range. The simulated values do not completely bracket 
the observations because uncertainty related to recharge error, model structural error and observational error is not taken into account.

\section{Quantile Mapping Results}

Systematic bias is removed from a simulated hydrograph by the process of quantile mapping; however, it will retain its signal when transposed. The fit of the transposed hydrograph is therefore influenced by the shape of the original simulated time-series and the similarity of each observed hydrograph to the original modelled hydrograph. Table II shows the RMSE (calculated on the hydrograph extremes) and Nash-Sutcliffe criterion for several transposed hydrographs in each group, highlighting an increase and decrease in error depending on the observed dataset. Where sections of the observed hydrograph have been reconstructed, the error is calculated on the period of time for which observed data are available (i.e. not on the reconstructed sections). The hydrograph for Blowing Stone Cottage, which required no reconstruction, transposed from Baydon Hole is given as an example (Figure 9). The peak of 1990 is comparatively high on the original modelled Baydon Hole hydrograph (Figure 8) and has therefore mapped to a high value on the observed Blowing Stone Cottage distribution. The peak of 1990 at Blowing Stone Cottage was less significant resulting in an overestimation by the simulated hydrograph. Translation of the modelled hydrograph signal will not always result in a decrease in model performance. Poor simulation of the observed maxima of Baydon Hole between 1977 and 1979 is translated to Blowing Stone Cottage. However, the observed hydrograph of Blowing Stone Cottage has a slightly different signal to Baydon Hole and the error is therefore lower on the transposed hydrograph.

In order to assess the impact of the quantile mapping method on model uncertainty, the best 50,000 models based on the RMSE of the hydrograph extremes and the 1st and 100th best models based on the Nash Sutcliffe criterion for Baydon Hole are transposed to the other observed hydrographs within group 1. The results are evaluated by calculation of the objective functions as above (Table III). The transposition process results in the removal of systematic bias from each validated model and reduces some of the model uncertainty so there is less difference between the 1st and 50,000th models after they have been transposed. This can be seen by the differences in the errors shown in Table III and by comparison of Figures 8 and 9. 


\section{WATER TABLE CONSTRUCTION}

Transposition of each model to other observed hydrographs within the same group provides a suite of modelled hydrographs for 52 boreholes across the Pang and Lambourn catchments over the time period 1975-2004. Spatial interpolation of modelled groundwater levels and river elevations allows a water table surface to be constructed for different points in time. The River Pang, Lambourn, Thames and Kennet act as important discharge points for groundwater thereby exerting a control on the water table surface. The River Thames and Kennet are comparably large perennial rivers and remain relatively constant in time within the study area; however, the lengths of the River Pang and River Lambourn are highly dependent on groundwater level and therefore fluctuate seasonally. The river extents are taken as the perennial river sections plus the ephemeral sections that are known to be flowing during average but not extreme winters (Figure 10A). Using GIS, points are inserted at regular intervals along each river and the elevations are extracted from a 50-m digital terrain model (Morris and Flavin, 1990) and incorporated into the water table surfaces.

Water table surfaces are produced for the first day of every month from November 2000 to April 2001. Those for December 2000 and January-March 2001 are shown in Figure 10. The Universal Kriging method is employed using a rational quadratic empirical semivariogram model as this provides the best linear unbiased estimation for spatial interpolation. This has been shown to be one of the most appropriate interpolation methods for contouring groundwater level data, which is generally a nonstationary variable (Gundogdu and Guney, 2007). The water table surfaces are compared to the ground surface, represented by the $50 \mathrm{~m}$ digital terrain model, allowing areas of groundwater emergence to be determined (Figure 10). The spatial extent of flooding is validated against observed flood extent data for the 2000/2001 event (Figure 10A). The flood extent in the Lambourn catchment is determined from field mapping (Robinson et al., 2001). This provides a good indication of the longitudinal sections of the valleys that were inundated during winter 2000/2001 but contains no information on the extent of flooding across the valleys. The exact timing of this mapping is also unknown. The flood extent in the Pang catchment is derived from an aerial photographic survey which was carried out in mid-January 2001, giving a more accurate representation of the temporal and spatial distribution of flooding. In order to quantify the similarity between the observed and simulated extent of flooding, the length of flooded sections in both catchments is measured (Table IV). For the Lambourn catchment, the length of the observed and simulated flooded sections is measured along the main valley upstream 
of Upper Lambourn village, the valley on the western side of the main valley at Upper Lambourn, the valley on the eastern side of the main valley at Lambourn village, the Great Shefford valley and the Winterbourne valley. In the Upper Pang catchment, measurements are made of the length of flooded sections in the western and eastern valleys north of Compton.

The November water table surface does not generate groundwater emergence upstream of the ephemeral river sections known to be flowing during average winters. In December 2000 the observed groundwater levels in the Upper Lambourn are above the average winter groundwater maxima and the modelled water table surface indicates a small amount of emergence in the Upper Lambourn catchment (Figure 10A). This is consistent with observations by farmers located on the Chalk scarp slope in the northern part of the Lambourn catchment, who reported flooding as early as November 2000. In the Upper Lambourn valley, extensive flooding can be seen from the modelling from January through to March 2001 (Figure 10B-D), which is consistent with the timing of a double peak on the observed hydrographs of nearby boreholes (e.g. Baydon Hole). Comparison with the mapped flood extent (Figure 10A) shows there is generally good agreement at the top of the Lambourn; however, there is an overestimation of the extent of flooding in the western dry valley and an underestimation in the main valley and eastern dry valley (Table IV). The modelled hydrographs for boreholes in the Upper Lambourn valley accurately simulate the magnitude of groundwater peaks during the 2000/2001 flood event and therefore discrepancies may be due to insufficient control on the groundwater surface as a result of lower data density in this area. Observed flooding in the main valley of the Upper Lambourn catchment is also known to be related to localized spring discharge. This may result from lateral flow of groundwater in perched horizons, which is not simulated by the model and therefore not incorporated into the water table surface.

Groundwater is initially observed at the surface in the Great Shefford dry valley in January 2001 (Figure 10B). The timing of this initial emergence is consistent with the observed hydrograph of Northfield Farm, which lies approximately $1.5 \mathrm{~km}$ upstream of Great Shefford village. This hydrograph reaches a maximum value in January 2001 and remains at this level until April 2001. The modelled flood extent expands up the valley in February (Figure 10C) and reaches a maximum in March (Figure 10D), when it closely resembles the mapped flood extent (Table IV). Due to a lack of data the timing of flooding further up the valley is 
unknown. The modelled flood extent also progressively expands up the Winterbourne valley, closely simulating the mapped flood extent in the upper valley in March and April (Figure 10D; Table IV). This timing is consistent with the observed hydrographs of Chapel Farm and Chapel Wood which display maxima in late February. The modelled water table surfaces reproduce the beginning of groundwater emergence in the Upper Pang in January, with an increase in February and March (Figure 10). The aerial survey was flown on 12 January and therefore the observed flood for extent would be expected to lie between the simulated extent 01/01/01 and 01/02/01. This is the case for the flooded length in the western dry valley north of Compton; however, there is an underestimation of the flooded length of the eastern dry valley (Table IV).

\section{DISCUSSION}

As has been observed in past events, flooding caused by groundwater emergence at the land surface has the potential to cause significant damage and prolonged disruption. There is a current need for a simple and widely applicable tool to assess the risk in vulnerable areas, enable better flood forecasting and allow an assessment of the potential impacts of climate change. The methodology developed here provides a rapidly applicable tool for simulating a water table surface without the need to develop a costly distributed numerical model for this purpose. This surface can be constructed for any point in time and used to identify potential areas of groundwater emergence. As was demonstrated during the winters of 2000/2001 and 2002/2003 chalk catchments are particularly susceptible to groundwater flooding and there are potential applications for this tool across significant portions of the United Kingdom and Europe where groundwater flooding is a risk.

At present the methodology has only been tested in the two catchments described in this article. Further validation is therefore required to assess its wider applicability. Additional work is required to determine the dependence of the results on the density of the observation borehole network as this is likely to affect the accuracy of the interpolated groundwater surface. Although this is not addressed in the article, observed records could be removed from the process in order to test the sensitivity of the results to data density and the applicability of the methodology to less intensively monitored catchments. Other factors such as topography and catchment hydrogeology are likely to impact the results and therefore more work is also required to test the ability of the methodology to reproduce groundwater flood extents in different hydrogeological settings. There is little groundwater abstraction in 
the Pang and Lambourn catchments, but abstraction could be incorporated into the lumped parameter model for application of the methodology to exploited aquifers. In this study, model simulations are undertaken using a monthly time step and it is therefore possible that groundwater extremes at the sub-monthly time-scale may be missed. This is a limitation imposed by the majority of available observational data.

Application of the methodology for the prediction of groundwater flooding under future climate simulations could be used to assess potential future flood risk. There are two limitations of the methodology presented here which would need to be addressed in such a study. First, the use of quantile mapping to transpose predicted groundwater hydrographs requires comparison of simulated future groundwater levels with simulated historic groundwater levels, posing a problem where the former lie outside the range of the latter. Second, the use of Monte Carlo sampling raises questions about model predictive uncertainty which would require further exploration for predictive purposes. Several methods have been suggested for applying quantile mapping where future simulated values lie outside the range of historic simulated values. Hamlet et al. (2002) suggest that where future values are within \pm 3.5 SDs of historic values, a fitted log-normal distribution can be used to extend the distribution of the historic dataset. Where future values lie outside \pm 3.5 SDs of historic values, a simple rescaling based on the fraction of the long-term mean can be used to translate between future and historic datasets. Model uncertainty related to the variation in the input parameters has not been quantified in this article; however, it is shown to be relatively small over the calibration and validation period and reduces when quantile mapping is applied. However, this cannot be inferred for model prediction, therefore the multicriteria or GLUE methodologies could be used to quantify predictive uncertainty for future application of the method in order that all potential groundwater scenarios are addressed when assessing the future flood risk.

\section{CONCLUSIONS}

Groundwater hydrographs in chalk catchments are notoriously difficult to model because of the particular hydraulic properties of the material and the spatial heterogeneity of the aquifer. The classification of groundwater hydrographs using PCA and CA provides a quantification of the spatial and temporal variations in groundwater behaviour, allowing representative hydrographs to be modelled. The method of quantile mapping has been shown to effectively transpose simulated hydrographs to other observed hydrographs providing a relatively fast 
method for producing a suite of point models. The spatial interpolation of point models, which are based on a simplified representation of the chalk, allows a time-variant water table surface to be created. Comparison with the ground surface enables areas of groundwater emergence to be determined for different points in time. The methodology has been shown to accurately represent the spatiotemporal occurrence of groundwater flooding in the Pang and Lambourn catchments during the 2000/2001 flood event. It therefore has potential application as a flood risk assessment tool, particularly under future climate scenarios, and would also be applicable to studies of drought conditions.

\section{Acknowledgements}

The work was undertaken as part of a Natural Environmental Research Council funded project (NE/E002307/1) under the Flood Risk from Extreme Events (FREE) Programme. This paper is published with the permission of the Executive Director of the British Geological Survey (Natural Environmental Research Council). 


\section{References}

Adams B, Bloomfield J, Gallagher A, Jackson C, Rutter H and Williams A. 2008. FLOOD1 Final Report. British Geological Survey Internal Report IR/06/033.

Allen DJ, Brewerton LJ, Coleby LM, Gibbs BR, Lewis MA, MacDonald AM, Wagstaff SJ, Williams AT. 1997. The physical properties of major aquifers in England and Wales. British Geological Survey Technical Report WD/97/34. Nottingham, UK: 312.

Bates BC, Kundzewicz ZW, Wu S and Palutikof J (Eds). 2008. Climate Change and Water. Technical Paper of the International Panel on Climate Change, IPCC Secretariat. Geneva: 210.

Beven K. 2001. Rainfall-Runoff Modelling: The Primer. John Wiley \& Sons Ltd., England.

Beven K. 2003. A manifesto for the equifinality thesis. Journal of Hydrology 320(1-2): 1836.

Bradford RB. 2002. Controls on the discharge of Chalk streams of the Berkshire Downs, UK. Science of the Total Environment 282: 65-80.

Calver A. 1997. Recharge Response Functions. Hydrology and Earth System Sciences 1: 4753.

Davis JC. 1986. Statistics and Data Analysis in Geology. John Wiley \& Sons, Inc., USA.

Duan QY, Sorooshian S and Gupta V. 1992. Effective and efficient global optimization for conceptual rainfall-runoff models. Water Resources Research 28(4): 1015-1031.

Finch J, Bradford WRB and Hudson JA. 2004. The spatial distribution of groundwater flooding in a chalk catchment in southern England. Hydrological Processes 18(5): 959971.

Grapes T, Bradley RC and Petts GE. 2005. Dynamics of river-aquifer interactions along a chalk stream: the River Lambourn, UK. Hydrological Processes 19(10): 2035-2053.

Green C, Wilson T, Masterson T and Boothby N. 2006. An assessment of the additional flood losses associated with groundwater flooding: a report to Hampshire County Council and Winchester City Council. Flood Hazard Research Centre, Middlesex University.

Griffiths J, Binley A, Crook N, Nutter J, Young A and Fletcher S. 2006. Streamflow generation in the Pang and Lambourn catchments, Berkshire, UK. Journal of Hydrology 330(1-2): 71-83.

Grindley J. 1967. The estimation of soil moisture deficits. Met. Mag. London 96 (1137): $97-$ 108.

Gundogdu KS and Guney I. 2007. Spatial analyses of groundwater levels using universal kriging. Journal of Earth System Science 116(1): 49-55.

Hamlet. A.F., Snover, A. and Lettenmaier, D.P. 2002. Climate Change Scenarios for Pacific Northwest Water Planning Studies: Motivation, Methodologies and a User's Guide to Applications. URL<

http://www.ce.washington.edu/ hamleaf/climate_change_streamflows/technical_docu mentation.pdf> [Accessed 26/07/09]

Hannah DM, Smith BPG, Gurnell AM and McGregor GR. 2000. An approach to hydrograph classification. Hydrological Processes 14(2): 317-338.

Hashino T, Bradley AA, Schwartz SS. 2007. Evaluation of bias-correction methods for ensemble streamflow volume forecasts. Hydrology and Earth System Sciences 11(2): 939-950. 
Ireson AM, Wheater HS, Butler AP, Mathias SA, Finch J and Cooper JD. 2006. Hydrological processes in the Chalk unsaturated zone - Insights from an intensive field monitoring programme. Journal of Hydrology 330(1-2): 29-43.

Ireson AM, Mathias SA, Wheater HS, Butler AP and Finch J. 2009. A model for flow in the chalk unsaturated zone incorporating progressive weathering. Journal of Hydrology 365: $244-260$

Jackson CR, Hughes AG and Mansour MM. 2005. Numerical modelling of groundwater flow to Gatehampton. British Geological Survey Commissioned Report CR/06/205C.

Keating T. 1982. A lumped parameter model of a chalk aquifer-stream system in Hampshire, United-Kingdom. Ground Water 20(4): 430-436.

Korkmaz S, Ledoux E and Onder H. 2009. Application of the coupled model to the Somme river basin. Journal of Hydrology 366(1-4): 21-34.

Kuczera G and Parent E. 1998. Monte Carlo assessment of parameter uncertainty in conceptual catchment models: the Metropolis algorithm. Journal of Hydrology 211(14): $69-85$.

Lee LJE, Lawrence DSL and Price M. 2006. Analysis of water level response to rainfall and implications for recharge pathways in the Chalk aquifer, SE England. Journal of Hydrology 330(3-4): 604-620.

Mahmood-ul-Hassan A and Gregory PJ. 2002. Dynamics of water movement on Chalkland. Journal of Hydrology 257(1-4): 27-41.

Mansour MM and Hughes AG. 2004. User's manual for the distributed recharge model ZOODRM. British Geological Survey Internal Report. IR/04/150.

Marechal JC, Ladouche B and Dorfliger N. 2008. Karst flash flooding in a Mediterranean karst, the example of Fontaine de Nimes. Engineering Geology 99(3-4): 138-146.

Marsh TJ and Dale M. 2002. The UK floods of 2000-2001: A hydrometeorological appraisal. Meeting of the Central Southern Branch of the Chartered-Institute-of-Water-andEnvironmental-Management, Wallingford, England.

Mathias SA, Butler AP, McIntyre N and Wheater HS. 2005. The significance of flow in the matrix of the Chalk unsaturated zone. Journal of Hydrology 310(1-4): 62-77.

Moon SK, Woo NC and Lee KS. 2004. Statistical analysis of hydrographs and water-table fluctuation to estimate groundwater recharge. Journal of Hydrology 292(1-4): 198-209.

Morris DG and Flavin RW. 1990. A digital terrain model for hydrology. Proc $4^{\text {th }}$ International Symposium on Spatial Data Handling. Vol. 1, Jul 23-27, Zurich: 250-262

Najib K, Jourde H and Pistre S. 2008. A methodology for extreme groundwater surge predetermination in carbonate aquifers: Groundwater flood frequency analysis. Journal of Hydrology 352(1-2): 1-15.

Penman HL. 1948. Natural evaporation from open water, bare soil and grass. Proc. R. Soc. London, Ser. A. 194, 120-146.

Pinault JL, Amraoui N and Golaz C. 2005. Groundwater-induced flooding in macroporedominated hydrological system in the context of climate changes. Water Resources Research 41(5).

Price M, Low RG and McCann C. 2000. Mechanisms of water storage and flow in the unsaturated zone of the Chalk aquifer. Journal of Hydrology 233(1-4): 54-71.

Robinson V, Solomon J and Morris S. 2001. Groundwater flooding in the Thames region, winter 2000/01, Environment Agency. 
Vrugt JA, Diks CGH, Gupta HV, Bouten W and Verstraten JM. 2005. Improved treatment of uncertainty in hydrologic modeling: Combining the strengths of global optimization and data assimilation. Water Resources Research 41(1): 17.

Vrugt JA, Gupta HV, Bastidas LA, Bouten W and Sorooshian S. 2003. Effective and efficient algorithm for multiobjective optimization of hydrologic models. Water Resources Research 39(8): 19.

Vrugt JA, Gupta HV, Bouten W and Sorooshian S. 2003. A Shuffled Complex Evolution Metropolis algorithm for optimization and uncertainty assessment of hydrologic model parameters. Water Resources Research 39(8): 18.

Wellings SR. 1984. Recharge of the upper chalk aquifer at a site in hampshire, england .1. Water-balance and unsaturated flow. Journal of Hydrology 69(1-4): 259-273.

Williams A, Bloomfield J, Griffiths K and Butler A. 2006. Characterising the vertical variations in hydraulic conductivity within the Chalk aquifer. Journal of Hydrology 330(1-2): 53-62.

Winter TC, Mallory SE, Allen TR and Rosenberry DO. 2000. The use of principal component analysis for interpreting ground water hydrographs. Ground Water 38(2): 234-246. 
Table I: Parameters and ranges used in the initial and final Monte Carlo run for each model (all groundwater level (Gwl) and elevation (h) values in $\mathrm{m} \mathrm{aOD}$; all $\mathrm{K}$ values in $\mathrm{md}^{-1}$ ).

\begin{tabular}{|c|c|c|c|c|c|c|c|}
\hline \multirow{2}{*}{$\begin{array}{c}\text { Model } \\
\text { Parameter }\end{array}$} & \multirow{2}{*}{$\begin{array}{l}\text { Initial } \\
\text { Range }\end{array}$} & \multicolumn{6}{|c|}{ Final Range } \\
\hline & & $\begin{array}{c}\text { Baydon } \\
\text { Hole }\end{array}$ & Inholmes & $\begin{array}{c}\text { Gibbet } \\
\text { Cottages }\end{array}$ & Woodend & Longacre & Winterbourne \\
\hline $\begin{array}{c}\text { Gwl } \\
\text { Range }\end{array}$ & & $130-155$ & $102-120$ & $102-132$ & $74-95$ & $124-135$ & $86-94$ \\
\hline $\mathbf{h}_{\mathbf{a}}$ & $\begin{array}{l}\text { As Gwl } \\
\text { Range }\end{array}$ & $130-135$ & $102-104$ & $102-104$ & $74-75$ & $124-125$ & $86-87$ \\
\hline $\mathbf{h}_{\mathrm{p}}$ & $\begin{array}{l}\text { As Gwl } \\
\text { Range }\end{array}$ & $135-140$ & 106-108 & $110-112$ & $82-84$ & $127-128$ & $86-89$ \\
\hline $\mathbf{h}_{\mathrm{b}}$ & $\begin{array}{l}\text { As Gwl } \\
\text { Range }\end{array}$ & $140-154$ & $112-119$ & $122-126$ & $87-91$ & $128-133$ & $87-94$ \\
\hline $\mathbf{h}_{\mathbf{w}}$ & $\begin{array}{l}\text { As Gwl } \\
\text { Range }\end{array}$ & $150-155$ & $113-119$ & $126-132$ & $88-95$ & $128-135$ & $92-94$ \\
\hline $\mathbf{K}_{\mathbf{p}}$ & $0.1-200$ & $40-70$ & $88-96$ & $22-28$ & $20-27$ & $139-155$ & $135-170$ \\
\hline $\mathbf{K}_{\mathbf{w}}$ & $0.1-200$ & $1-200$ & $1-200$ & $1-200$ & $1-200$ & $1-200$ & $390-500$ \\
\hline $\mathbf{S}_{\mathrm{p}}$ & 0.001-0.09 & $0.007-0.02$ & $0.01-0.03$ & $0.009-0.02$ & $0.012-0.03$ & $0.02-0.05$ & $0.04-0.09$ \\
\hline $\mathbf{S}_{\mathrm{w}}$ & $0.001-0.09$ & $0.001-0.09$ & 0.001-0.09 & 0.001-0.09 & $0.001-0.09$ & $0.001-0.09$ & $0.001-0.09$ \\
\hline $\mathbf{n}$ & & 5 & 5 & 6 & 5 & 6 & 5 \\
\hline $\begin{array}{l}\mathbf{k} \\
\lambda\end{array}$ & final range & $\begin{array}{c}1-7 \\
0.1-\mathrm{n}\end{array}$ & $\begin{array}{c}1-7 \\
0.1-\mathrm{n}\end{array}$ & $\begin{array}{c}1-7 \\
0.1-n\end{array}$ & $\begin{array}{c}1-7 \\
0.1-n\end{array}$ & $\begin{array}{c}1-7 \\
0.1-\mathrm{n}\end{array}$ & $\begin{array}{c}1-7 \\
0.1-n\end{array}$ \\
\hline
\end{tabular}


Table II: Results of the best calibrated model (C) determined by the RMSE calculated on the hydrograph extremes for each simulated hydrograph; results when this model is run over the validation period (V); best and worst example of model transposition from each group when the model of the validation period is transposed to observed hydrographs by the process of quantile mapping. Blowing Stone Cottage is also shown in Group 1 as this is given as an example in Figure 9.

\begin{tabular}{llcc}
\hline & Hydrograph & $\begin{array}{c}\text { RMSE of hydrograph } \\
\text { Extremes }\end{array}$ & Nash Sutcliffe Criterion \\
\hline Group 1 & Baydon Hole (C) & 1.83 & 0.83 \\
& Baydon Hole (V) & 2.07 & 0.82 \\
& Marsh Benham & 0.60 & 0.74 \\
& Kingston Hill Barn & 2.79 & 0.77 \\
& Blowing Stone Cottage & 1.59 & 0.78 \\
Group 2 & Inholmes (C) & 1.06 & 0.88 \\
& Inholmes (V) & 1.25 & 0.82 \\
& Northfield Farm & 0.89 & 0.74 \\
& The Barracks & 2.27 & 0.74 \\
Group 3 & Gibbet Cottages (C) & 2.98 & 0.86 \\
& Gibbet Cottages (V) & 3.26 & 0.81 \\
& Brightwalton Common & 1.36 & 0.72 \\
& Malthouse & 2.50 & 0.78 \\
Group 4 & Woodend (C) & 1.72 & 0.81 \\
& Woodend (V) & 2.03 & 0.60 \\
& Springfield Road & 1.05 & 0.34 \\
& Lower Chance Farm & 2.83 & 0.67 \\
& Winterbourne (C) & 0.35 & 0.61 \\
& Winterbourne (V) & 0.78 & 0.53 \\
& Longacre (C) & 0.66 & 0.71 \\
& Longacre (V) & 2.12 & 0.32 \\
\hline \multirow{4}{*}{ Anomalies } & & \\
& & &
\end{tabular}


Table III: Model results when a suite of calibrated models for Baydon Hole are validated and transposed to other observed hydrographs within group 1 (best and worst results are shown).

\begin{tabular}{|c|c|c|c|c|c|c|c|c|}
\hline \multirow[t]{2}{*}{ Calibrated Model } & \multicolumn{2}{|c|}{$\begin{array}{c}\text { Baydon Hole } \\
\text { Calibrated }\end{array}$} & \multicolumn{2}{|c|}{$\begin{array}{c}\text { Baydon Hole } \\
\text { Validated }\end{array}$} & \multicolumn{2}{|c|}{$\begin{array}{c}\text { Marsh Benham } \\
\text { Transposed }\end{array}$} & \multicolumn{2}{|c|}{$\begin{array}{c}\text { Kingston Hill Barn } \\
\text { Transposed }\end{array}$} \\
\hline & RMSE & NS & RMSE & $\mathbf{N S}$ & RMSE & NS & RMSE & NS \\
\hline $1^{\text {st }}($ RMSExt) & 1.83 & 0.83 & 2.07 & 0.82 & 0.60 & 0.74 & 2.79 & 0.77 \\
\hline $100^{\text {th }}($ RMSExt $)$ & 1.93 & 0.79 & 2.20 & 0.79 & 0.54 & 0.79 & 2.82 & 0.77 \\
\hline $1000^{\text {th }}($ RMSExt $)$ & 1.94 & 0.84 & 2.17 & 0.82 & 0.58 & 0.75 & 2.80 & 0.76 \\
\hline $10000^{\text {th }}($ RMSExt $)$ & 2.18 & 0.77 & 2.32 & 0.78 & 0.59 & 0.75 & 2.82 & 0.76 \\
\hline $500000^{\text {th }}($ RSMExt $)$ & 2.35 & 0.85 & 2.58 & 0.83 & 0.69 & 0.68 & 2.83 & 0.75 \\
\hline $1^{\text {st }}($ Nash Sutcliffe) & 2.02 & 0.86 & 2.26 & 0.85 & 0.67 & 0.70 & 2.71 & 0.77 \\
\hline $100^{\text {th }}$ (Nash Sutcliffe $)$ & 2.25 & 0.86 & 2.50 & 0.83 & 0.67 & 0.69 & 2.71 & 0.77 \\
\hline Error Range & 0.52 & 0.09 & 0.51 & 0.07 & 0.15 & 0.11 & 0.12 & 0.02 \\
\hline
\end{tabular}


Table IV: Length of the flood extent in the Upper Pang and Lambourn catchments from the observed data and modelled water table surfaces for December 2000 and January - March 2001.

\begin{tabular}{|c|c|c|c|c|c|}
\hline \multicolumn{6}{|c|}{ Lambourn Flooded Length (m) } \\
\hline & Observed & $01 / 01 / 01$ & $01 / 02 / 01$ & $01 / 03 / 01$ & $01 / 04 / 01$ \\
\hline $\begin{array}{c}\text { Winterbourne } \\
\text { Valley }\end{array}$ & 11041 & 7986 & 7986 & 11570 & 11442 \\
\hline $\begin{array}{c}\text { Great Shefford } \\
\text { Dry Valley }\end{array}$ & 4744 & 3849 & 4585 & 5135 & 4444 \\
\hline $\begin{array}{c}\text { Lambourn Dry } \\
\text { Valley }\end{array}$ & 2777 & 1057 & 0 & 1057 & 0 \\
\hline $\begin{array}{c}\text { Upper Lambourn } \\
\text { Main Valley }\end{array}$ & 2939 & 1968 & 1968 & 1968 & 1258 \\
\hline $\begin{array}{c}\text { Upper Lambourn } \\
\text { Dry Valley }\end{array}$ & 668 & 2630 & 1891 & 2630 & 1009 \\
\hline \multicolumn{6}{|c|}{ Pang Flooded Length (m) } \\
\hline & Observed & $01 / 01 / 01$ & $01 / 02 / 01$ & $01 / 03 / 01$ & $01 / 04 / 01$ \\
\hline $\begin{array}{l}\text { North of Compton } \\
\text { (East) }\end{array}$ & 5278 & 0 & 3512 & 3595 & 3595 \\
\hline $\begin{array}{c}\text { North of Compton } \\
\text { (West) }\end{array}$ & 5924 & 0 & 6246 & 6276 & 6355 \\
\hline
\end{tabular}


Figure 1. Location of the Pang and Lambourn catchments in the Berkshire Downs, UK

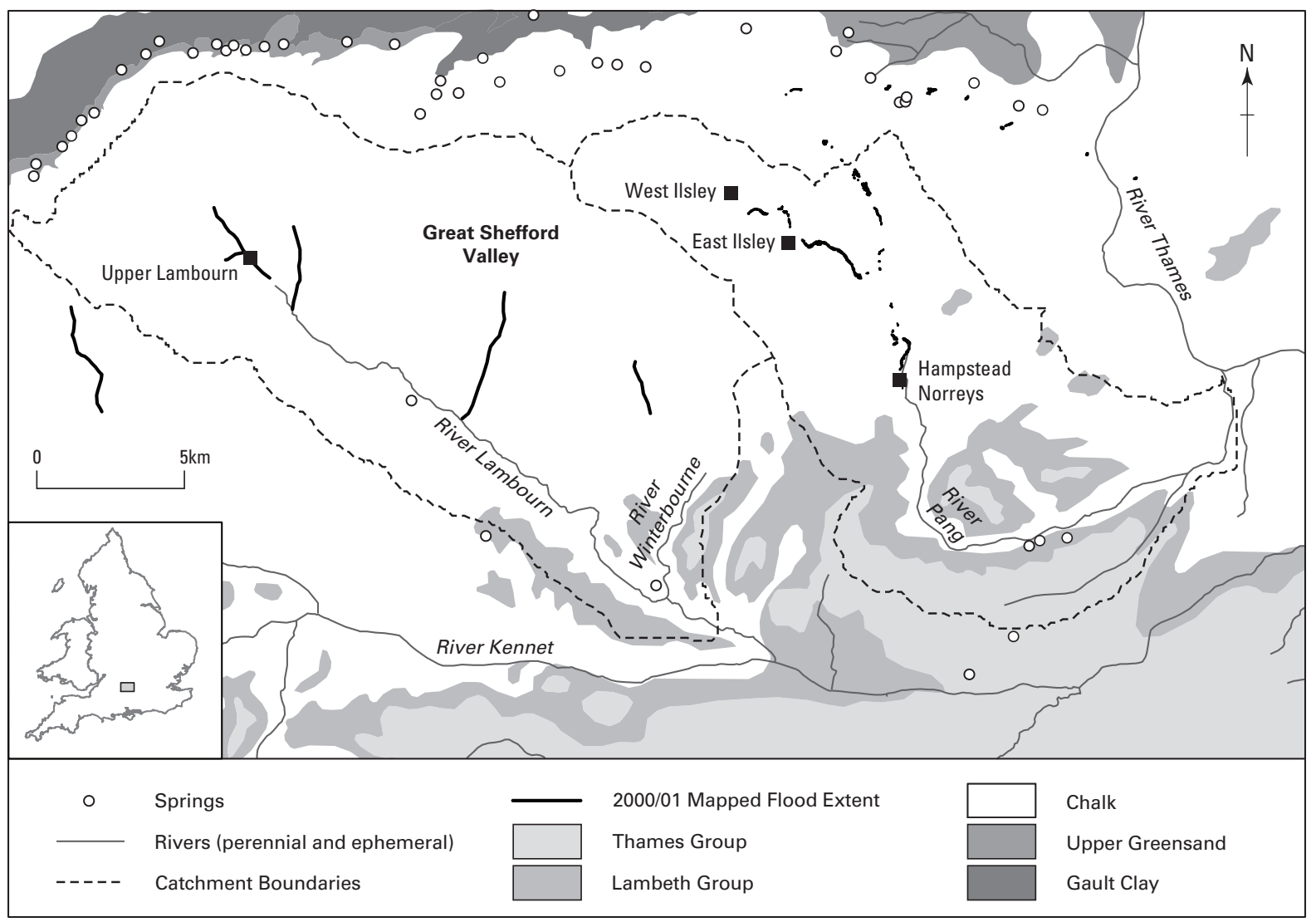

Figure 2. Dendrogram (A) and validity index plots (B) for hydrographs in the Pang and Lambourn from hierarchical CA carried out on the 1975-1983 component loadings of each groundwater level time-series onto the three principal components

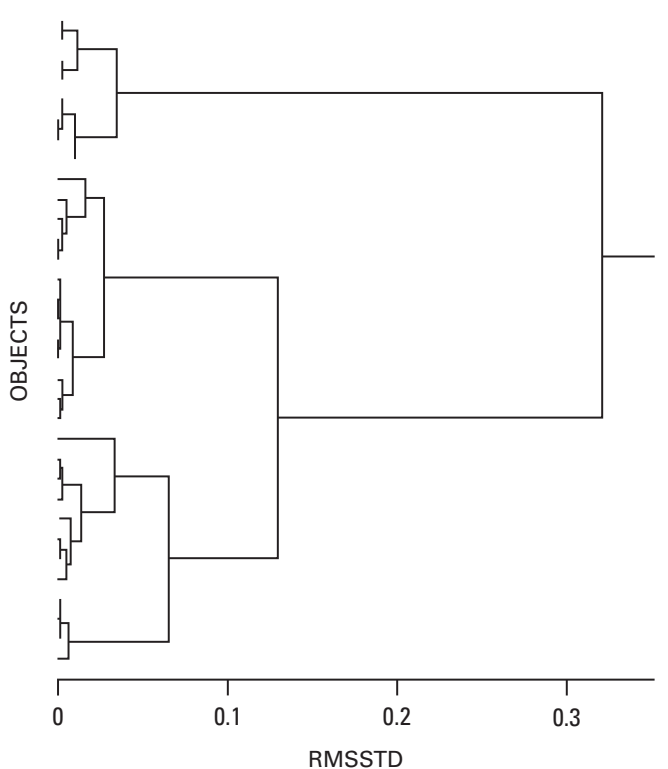

B

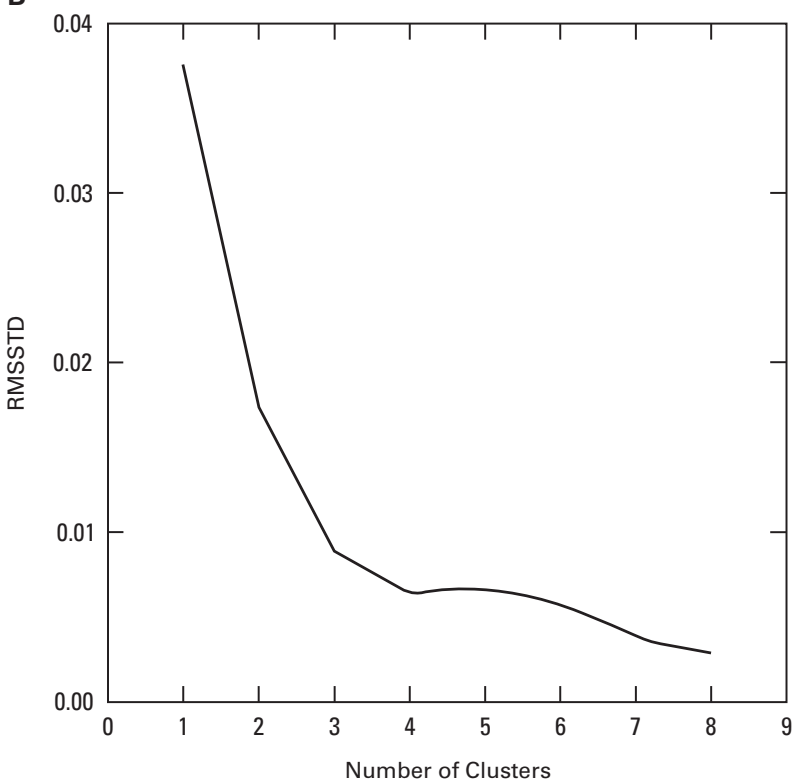


Figure 3. Normalized hydrographs in groups 1 (A) and 4 (B), as identified by PCA and CA
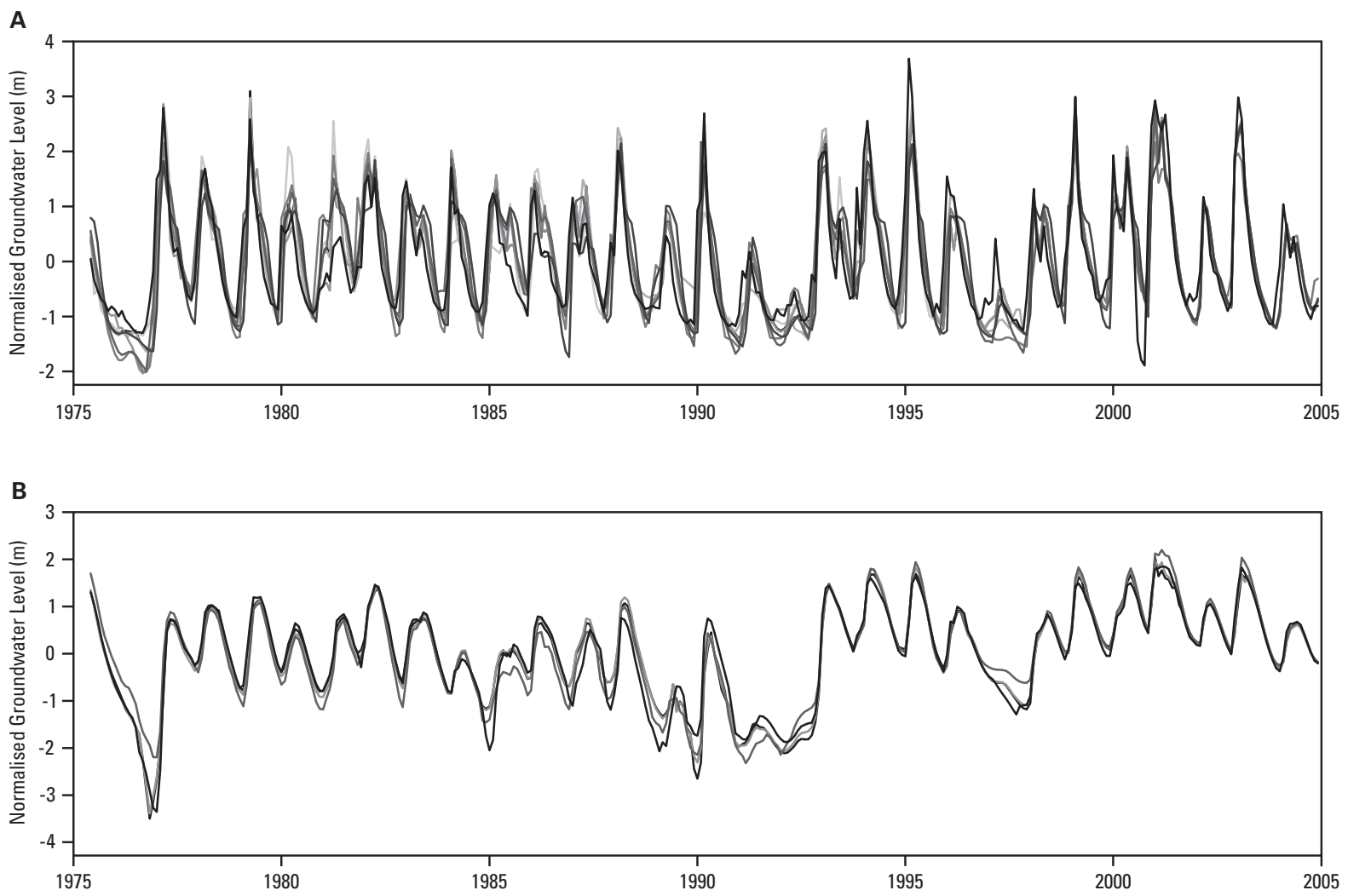

Figure 4. Location of modelled hydrographs and spatial distribution of hydrographs within each group

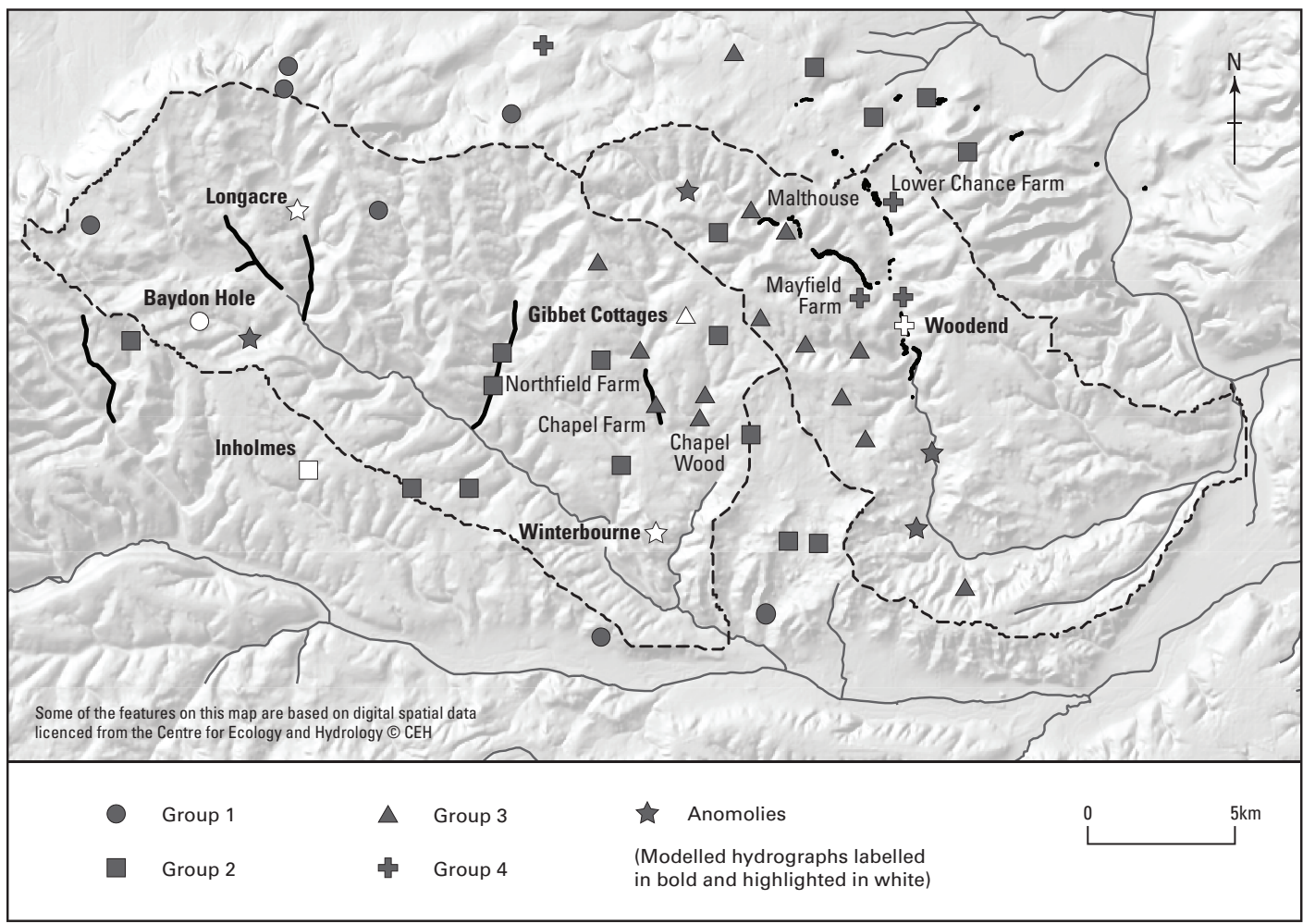


Figure 5. Lumped parameter model structure based on the aquifer model outlined by Keating (1982)

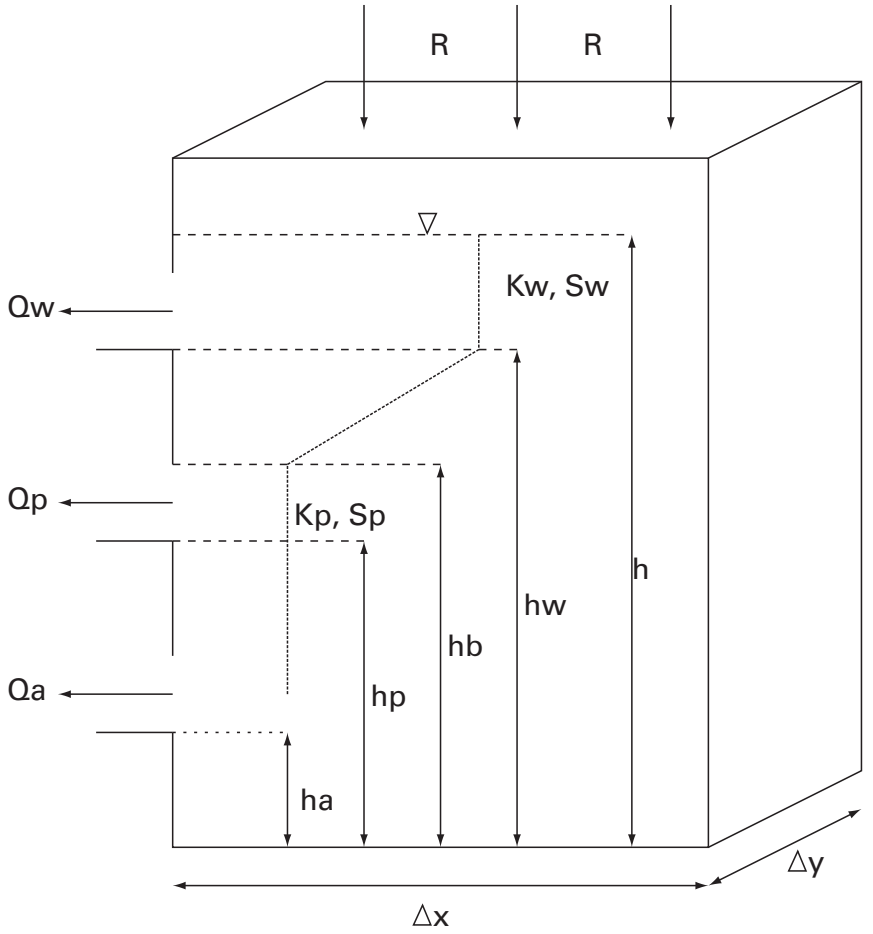


Figure 6. Scatter plots showing the identifiability (defined in text) of each aquifer model parameter from the initial Monte Carlo Run results (shown in black) and the improved results from the final Monte Carlo run when a reduced parameter space is defined for certain parameters (shown in grey)
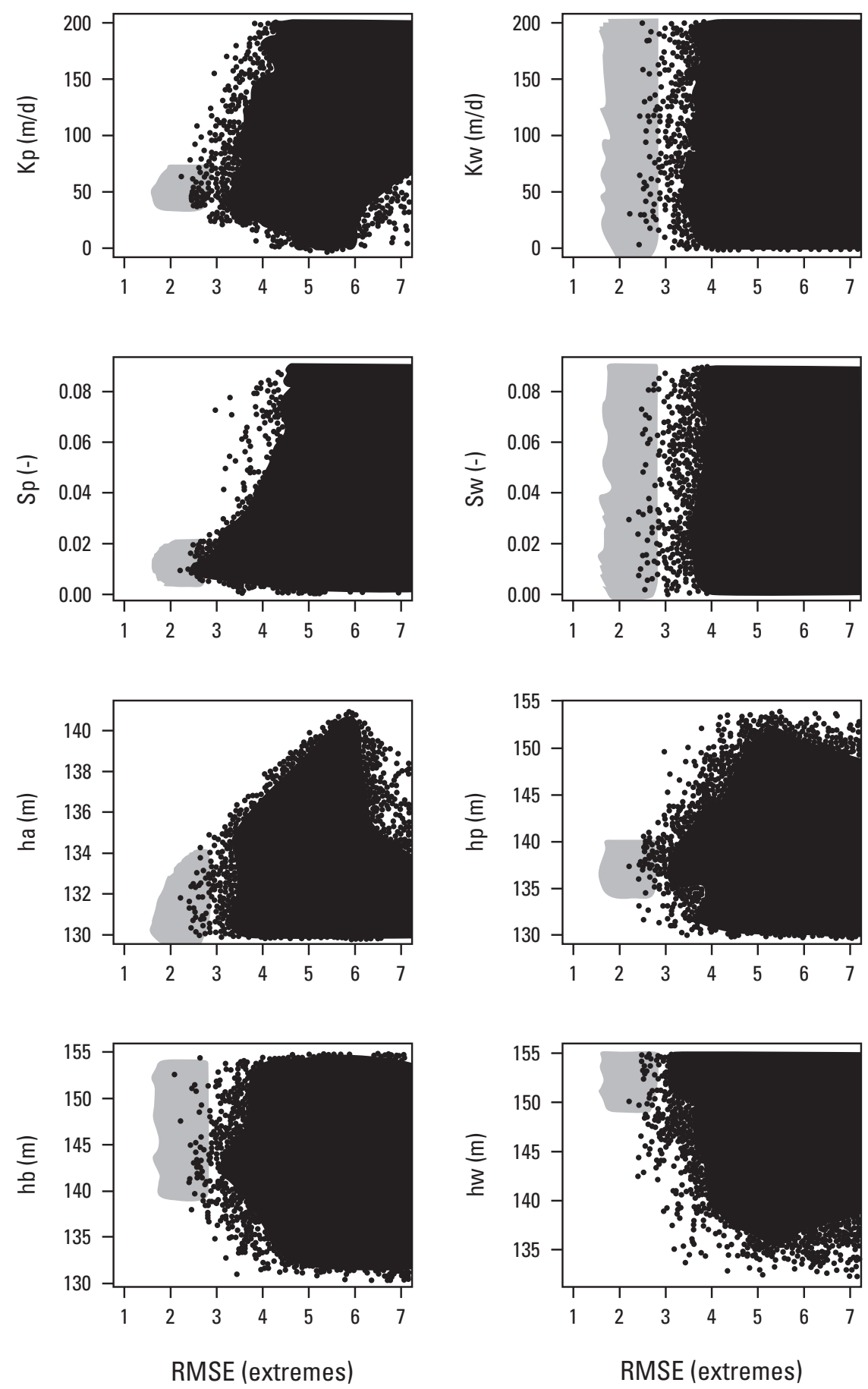
Figure 7. Monthly weightings of the transfer of recharge for the 200 best models from the final Monte Carlo run of Baydon Hole (group 1)

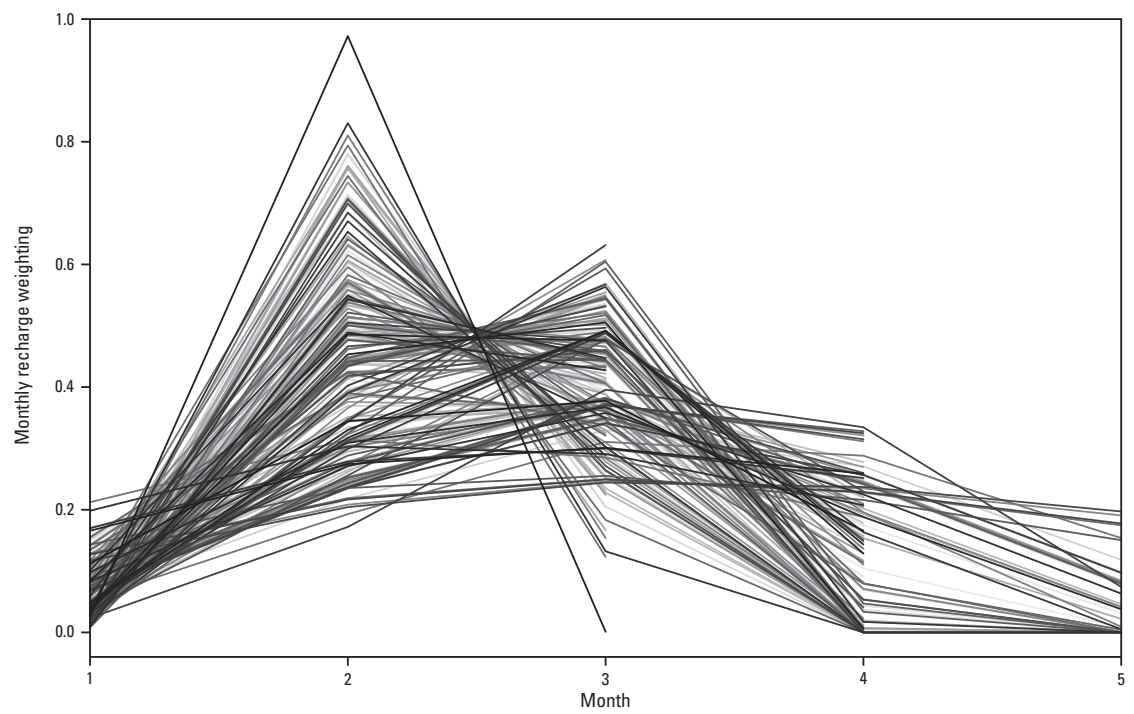

Figure 8. Simulated hydrographs of: (A) Baydon Hole (group 1) showing the 50,000 best calibrated models run over the validation period; and (B) Woodend, showing the best calibrated model run over the validation period (group 4)
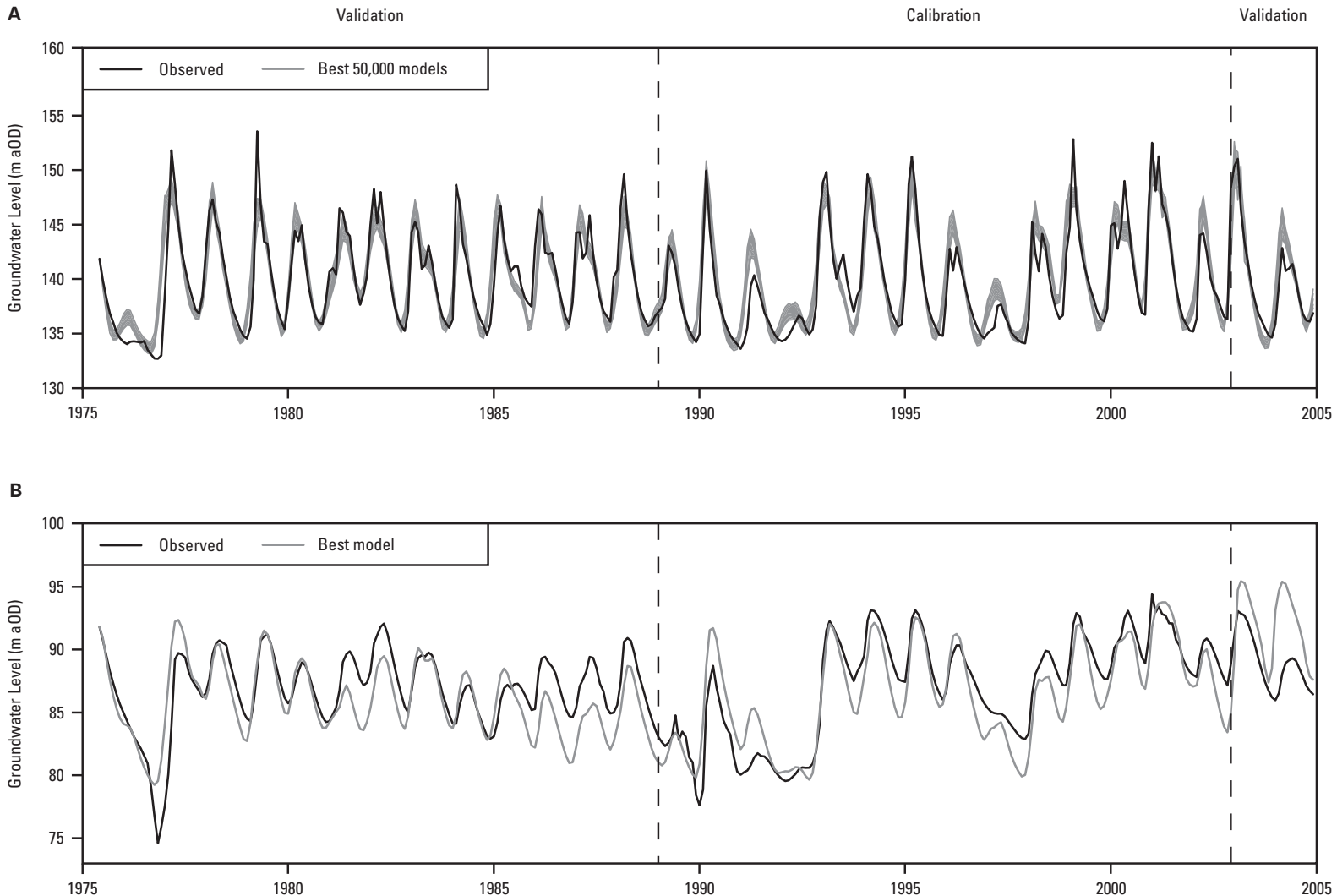
Figure 9. Simulated hydrographs of Blowing Stone Cottage (group 1), transposed from the modelled hydrograph of Baydon Hole. All models shown in Figure 8A are transposed and shown in this figure

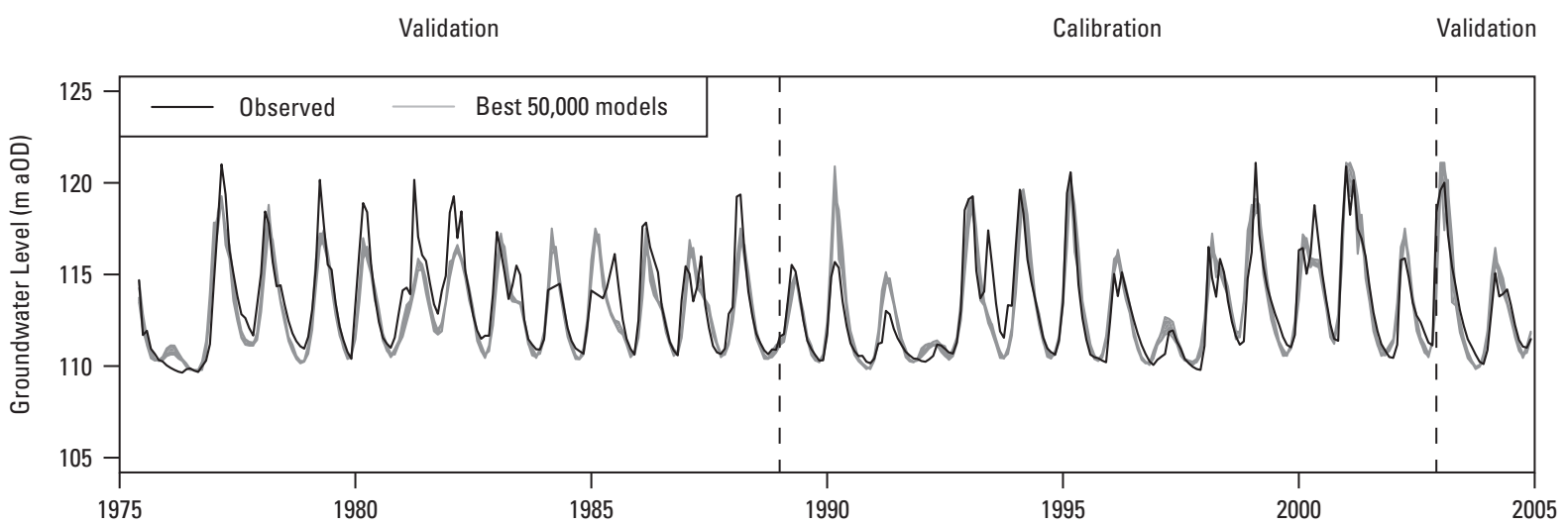

Figure 10. Simulated water table surfaces overlain on a 50-m digital terrain model to show areas of groundwater emergence on: (A) 1 December 2000; (B) 1 January 2001; (C) 1 February 2001; (D) 1 March 2001. Extent of rivers known to be flowing during wet but not extreme winters is also shown (A)

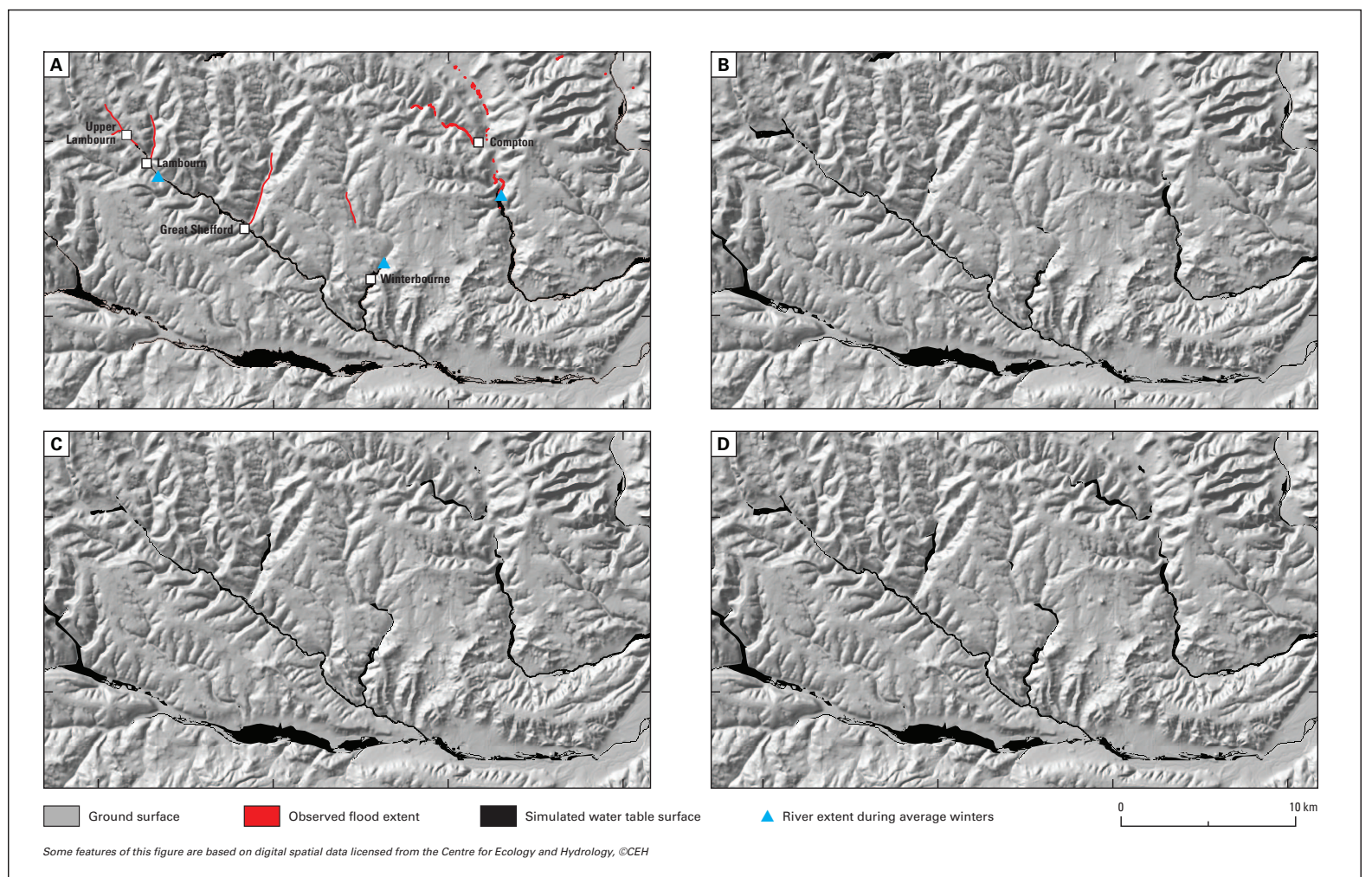

